\title{
New Method for In-situ Measurement of Pore Size Deformation of Barrier Textiles under Biaxial Loading
}

Kocaman RT ${ }^{1, *}$, Malik SA ${ }^{1,2}$, Aibibu $D^{1}$, Gereke $\mathrm{T}^{1}$ and Cherif $\mathrm{C}^{1}$

${ }^{1}$ Institute of Textile Machinery and High Performance Material Technology, Faculty of Mechanical Science and Engineering, Technische Universität Dresden, Hohe Straße 6, 01069, Dresden, Germany

${ }^{2}$ Department of Textile Engineering, Mehran University of Engineering and Technology, Jamshoro, Sindh, Pakistan

\begin{abstract}
The pore size is one of the vital morphological characteristics of barrier fabrics as it decisively affects their permeability and retention properties. Apart from fabric construction and material aspects, the pore size also depends on applied mechanical loads, which occur during typical usage life cycles. Among others, barrier fabrics such as surgical gowns are exposed to loads during their use. These loads have a significant effect on the fabric morphology which influences the permeability properties as well. In this study, a newly developed in situ pore size measurement method was used to measure the changes in pore size that occur in high density barrier woven fabrics under biaxial loadings and after cyclic loading. It was observed that, under tension, pore size distributions changed and mean flow pore sizes increased. Results revealed that the developed in situ measurement method has a great potential for the determination of pore size changes in barrier textiles under biaxial loading.
\end{abstract}

Keywords: In-situ pore size analysing; Barrier textiles; Porosity; Pore size measurement

\section{Introduction}

Several technical applications require textile structures that offer a combination of definite permeability and retention properties. Such applications may include fabrics for filtration as well as operating and clean room textiles. Operating room textiles, particularly surgical gowns and draping materials require forementioned contradictory characteristics to keep the wearer comfortable and simultaneously provide a barrier against particle-loaded fluids. Pore size is among the most important parameters influencing the barrier and filter effects of fabrics. Therefore, it is crucial to define pore size distributions of textile materials prior to usage. Surgical gowns can be manufactured from nonwovens (disposable), woven fabrics and trilaminates as hybrid systems (reusable) to attain the required protection and comfort [1]. High density polyester (PES) multifilament woven fabrics are commonly used for the manufacturing of surgical gowns due to their barrier effect, liquid impermeability and wearing comfort. The pore structure of a multifilament woven fabric is a combination of pores between the filaments of a yarn (inter-fiber pores or micropores) and pores between yarns (inter-yarn pores or mesopores) in the warp and weft directions [2,3]. This combination of inter-fiber and inter-yarn pores was used in study [4] for the characterisation of a woven filter. Pore size is a significant effect in preventing the strike through of contaminated fluids and particles through the fabric and defining air and vapour permeability $[5,6]$. Several processing and fabric construction factors and yarn parameters define the permeability and pore morphology of woven fabrics [7]. By use of these construction parameters theoretical and analytical air permeability models were developed and the effect of these parameters on permeability properties were discussed in several studies [8-12]. Surgical gowns made of woven fabrics are also subjected to tensile forces during their service life as well, e.g., during laundering which leads to morphological deformations. In studies [13-15], complex mechanical loads acting on surgical gowns during their application in surgical operations were analysed. It was found that surgical gowns are subjected to quasistatic and cyclic loads. These textiles were loaded by tension, pressure, shear and friction loads. These loads were approximated to $0.4 \mathrm{~N} / \mathrm{cm}^{2}$ for underarms and up to $20 \mathrm{~N} /$ $\mathrm{cm}^{2}$ for elbows. As a result of these multifaceted mechanical forces occurring during the daily use of protective textiles, the morphological characteristics of the woven fabric will change [16].

In these empirical studies, however, the change in pore morphology was not fundamentally investigated. Mechanical stresses (e.g., tensile, bending) lead to a significant change in the pore morphology of the woven fabric [17]. In studies [18] and [19] it was stated that the force-elongation behaviour of a woven fabric depends on both the yarn properties and the fabric structure, so that non-uniformities in the fabric structure affect not only the force-elongation behaviour of the fabric, but also its porosity under load. In study of Rukuiziene and Milasius [20], changes in the warp yarn crimp during mono- and biaxial tensile stresses as a function of the fabric width and the load as well as the fabric elongation as a function of the fabric width in the weft direction were investigated. It was concluded that it is very important to investigate the change in pore structure of woven fabrics under biaxial stresses. However, corresponding testing regimes were not presented in the study.

The porosity and pore size distribution of textiles can be investigated by means of different methods. A well-established method is the image analysis technique $[21,22]$, which is suitable for the determination of porosity in two-dimensional planes. In study of Chang et al. [23], a method of involving binarized images was used to determine the porosity change of carbon felt electrodes under various amounts of compressions. The binary image analysis, i.e., the counting of pixels for dark and bright regions, was used to measure porosity changes. However, a practical measurement of porosity changes of carbon felt

*Corresponding author: Kocaman RT, Institute of Textile Machinery and High Performance Material Technology, Faculty of Mechanical Science and Engineering, Technische Universität Dresden, Hohe Straße 6, 01069, Dresden, Germany, Tel: +49 351 463-39342; E-mail: recep_tuerkay.kocaman1@tu-dresden.de

Received April 12, 2018; Accepted April 19, 2018; Published April 29, 2018

Citation: Kocaman RT, Malik SA, Aibibu D, Gereke T, Cherif C (2018) New Method for In-situ Measurement of Pore Size Deformation of Barrier Textiles under Biaxial Loading. J Textile Sci Eng 8: 355. doi: 10.4172/2165-8064.1000355

Copyright: (c) 2018 Kocaman RT, et al. This is an open-access article distributed under the terms of the Creative Commons Attribution License, which permits unrestricted use, distribution, and reproduction in any medium, provided the original author and source are credited. 
after compression loading cannot be maintained. Furthermore, this type of optical measurement method considers only the material surface and is therefore not capable of measuring throughout the material depth. In study of Mühl et al. [24], high-resolution images of the textile implants with mesh structures were evaluated for measuring the two-dimensional pore size using an optical measurement method. The selected camera lens and optical geometry yield a minimum resolution of $10 \mu \mathrm{m}$. The combined color picture was converted into a grey scale image using transform coefficients. For fiber and pore detection, grey scale pictures were transferred into binary images via adaptive thresholding. By using the necessary erode and dilate functions, the pores were extracted and counted which fulfils the mentioned conditions. In these studies, porosity measurement methods were used to determine the porosity of the materials without causing deformation to the material. In a study of Klinge et al. [25], two-dimensional pore size changes exclusively during uniaxial loading of textile implants with mesh structures having a minimum pore size of $10 \mu \mathrm{m}$ were determined using the same image analysis method which was used in study [24]. However, materials such as surgical gowns and barrier textiles typically possess smaller pores, with sizes between $0.5 \mu \mathrm{m}$ to $20 \mu \mathrm{m}$ [5,7].

Another possibility for porosity measurement is the method which uses the process technique for the measurements. There are several pore size measurement methods, e.g., the mercury intrusion porometry method [26-28], bubble point method [29], capillary flow porometry [30] and liquid displacement method [31]. It is well known that there is a major difference between porosity and permeability properties of textile materials due to their volumetric porosity and porosity leading to permeability. Porosity refers to the ratio of total volume of voids to the complete volume within its boundaries, whereas permeability refers to the usability of this void for a liquid or gas to flow through $[26,27]$. It was also defined that the part of total porosity which allows the fluids to flow through is called "effective porosity". In textile materials, effective porosity is largely dependent upon inter-fiber and inter-yarn porosities. Measuring the pore size distribution is also a way of measuring effective porosity offering a broad idea about the porosity of material [27]. However, the mentioned methods and the pore size intervals are not suitable for the non-destructive measurement of pore sizes during loading.

An in situ analysis of the pore size changes of high density woven fabrics caused by external mechanical stresses, especially in the form of biaxial loading, has yet been lacking. Only Rief et al. [16] published a method for analysis of pore size changes under loading. In this method, the condition of the woven structure during stress application and immediately after it in a relaxed condition was fixed using a light hardening epoxy resin. The pore morphology was recorded microscopically. Despite the fact that this method is suitable for the determination of inter-fiber and inter-yarn porosities using an optical method, it does not determine the effective porosity. Based on this promising approach, a non-destructive in situ pore analysing method need to be developed. The presented research work offers a promising, novel and unique in situ method for the continuous non-destructive analysing of pore sizes in biaxial loading condition.

\section{Experimental}

\section{Materials}

11 woven fabrics were manufactured and analysed systematically in the present research according to the effect of fabric construction (fabric index and binding), process and yarn parameters. The construction and process parameters of manufactured fabrics are stated in Table 1. Based on sample 2 as model fabric, other samples were woven by varying the weft yarn, fabric index and fabric construction. In order to evaluate the influence of the machine speed on the structural properties of fabrics, the machine speed was varied in the range of $200 \mathrm{rpm}$ and $450 \mathrm{rpm}$. Weft densities were varied for obtaining different fabric indices. Fabric indices were calculated according to Walz-Luibrand [7,32,33]. Bindings as Plain 1/1 and Twill $2 / 2$ were also used in the chosen samples (Table 1 ).

PES multifilament yarns were used for the manufacturing of woven barrier fabrics. The multifilament yarns were purchased from Trevira, Germany. The detailed yarn parameters including their mentioned effects on porosity are listed in Table 2 . The weaving process was carried out on a rapier weaving machine PTS4/S EasyLeno (Lindauer Dornier, Germany). Asymmetric shed geometries (lower shed upper shed) were adopted and a full-width temple guide was used due to the insufficient function of conventional temple guides. The fabrics were desized on an air flow washing unit (Then, Hong Kong) and subsequently fixed at a coating machine (Coatema Coating Machinery, Germany) at a temperature of $200^{\circ} \mathrm{C}$ (Table 2).

\section{New non-destructive method for in situ pore size measurement under biaxial loading}

Pore size values and pore size distribution are integral to the permeability characteristics of woven fabrics by providing specific information regarding the pore structure of a fabric. Pore size and pore size distribution can be measured by the liquid displacement method using a pore size meter PSM 165 (Topas, Germany) [5,7,3336]. The basic principle of pore size measurement is that liquid-filled pores will become gas permeable at a certain gas flow pressure. This initial differential pressure indicates the bubble point of a material. The test fluid in the pores has to be displaced by gas first and the opening pressure depends on the surface tension of the fluid and the pore size

\begin{tabular}{|c|c|c|c|c|c|c|c|}
\hline Sample number & Warp yarn & Weft yarn & $\begin{array}{c}\text { Warp density } \\
{\left[\mathrm{cm}^{-1}\right]}\end{array}$ & $\begin{array}{l}\text { Weft density } \\
{\left[\mathrm{cm}^{-1}\right]}\end{array}$ & Binding & $\begin{array}{c}\text { Fabric index } \\
\text { (Walz- Luibrand) }\end{array}$ & $\begin{array}{c}\text { Machine speed } \\
{[\text { rpm] }}\end{array}$ \\
\hline 1 & Yarn 1 & Yarn 1 & 68 & 36 & Plain 1/1 & 0.9 & 200 \\
\hline 2 & Yarn 1 & Yarn 1 & 68 & 36 & Plain 1/1 & 0.9 & 300 \\
\hline 3 & Yarn 1 & Yarn 1 & 68 & 36 & Plain 1/1 & 0.9 & 400 \\
\hline 4 & Yarn 1 & Yarn 1 & 68 & 36 & Plain 1/1 & 0.9 & 450 \\
\hline 5 & Yarn 1 & Yarn 1 & 68 & 22 & Plain 1/1 & 0.55 & 300 \\
\hline 6 & Yarn 1 & Yarn 1 & 68 & 27 & Plain 1/1 & 0.68 & 300 \\
\hline 7 & Yarn 1 & Yarn 1 & 68 & 39 & Twill 2/2Z & 0.55 & 300 \\
\hline 8 & Yarn 1 & Yarn 1 & 68 & 48 & Twill 2/2Z & 0.68 & 300 \\
\hline 9 & Yarn 1 & Yarn 2 & 68 & 36 & Plain 1/1 & 0.9 & 300 \\
\hline 10 & Yarn 1 & Yarn 3 & 68 & 36 & Plain 1/1 & 0.9 & 300 \\
\hline 11 & Yarn 1 & Yarn 4 & 68 & 29 & Plain 1/1 & 0.9 & 300 \\
\hline
\end{tabular}

Table 1: Design of experiment - Selected samples with construction and process parameters. 


\begin{tabular}{|c|c|c|c|c|c|c|}
\hline Yarn type & Warp yarn & $\begin{array}{l}\text { Yarn fineness } \\
\text { [dtex] }\end{array}$ & $\begin{array}{c}\text { Filament } \\
\text { fineness [dtex] }\end{array}$ & $\begin{array}{c}\text { Filament diameter } \\
{[\mu \mathrm{m}]}\end{array}$ & $\begin{array}{l}\text { Longitudinal yarn view } \\
\text { (light microscopy, 100x) }\end{array}$ & $\begin{array}{l}\text { Mentioned effect on } \\
\text { porosity }\end{array}$ \\
\hline Yarn 1 & $\begin{array}{l}\text { Multifilament } 100 \text { dtex } \\
\text { f40 flat }\end{array}$ & 100 & 2.5 & 15.9 & & $\begin{array}{c}\text { As warp and weft yarn for } \\
\text { the model weave }\end{array}$ \\
\hline Yarn 2 & $\begin{array}{l}\text { Multifilament } 100 \text { dtex } \\
\text { f128 flat }\end{array}$ & 100 & 0.78 & 9.8 & & $\begin{array}{l}\text { As weft yarn/ } \\
\text { Effect of filament fineness }\end{array}$ \\
\hline Yarn 3 & $\begin{array}{l}\text { Multifilament } 100 \text { dtex } \\
\text { f80 textured }\end{array}$ & 100 & 1.25 & 14.6 & & $\begin{array}{l}\text { As weft yarn/ } \\
\text { Effect of texturing }\end{array}$ \\
\hline Yarn 4 & $\begin{array}{l}\text { Multifilament } 150 \text { dtex } \\
\text { f48 flat }\end{array}$ & 150 & 3.12 & 17.6 & & $\begin{array}{c}\text { As weft yarn/ } \\
\text { Effect of yarn fineness }\end{array}$ \\
\hline
\end{tabular}

Table 2: Properties of yarns used for weaving

diameter. Increasing at the pressure drop across the material during the test and measuring the volumetric flowrate generates sufficient data, in order to calculate the pore size distribution. A pore size range from 0.5 $\mu \mathrm{m}$ to $250 \mu \mathrm{m}$ can be measured. However, the existing device is not suitable for in situ measurements.

In the research study described in this paper, the challenge was to achieve the non-destructive measurement of pore size changes under biaxial loading. For this reason, a special sample holder including a measuring head was developed and connected to the standard measuring cell of the device in Topas, Germany (Figure 1). Air supply was linked from the test instrument to the special sample holder using a pressure measurement hose (Figure 1a). An additional hose for used gas was also connected to the test instrument in order to eject the used gas. Special sample holder was designed to take measurements at different points across loaded samples and this property gives flexibility for the measurements (Figure 1).

The woven fabric under tension can be clamped with this special sample holder and air can be carried to the clamped sample through pressure measurement hose. Hence, dry and wet flow measurements can be performed. The height of the sample holder was adjustable to be able to clench the tensioned woven fabric. Figure 2 reveals how the special sample holder was linked to the test instrument by the hoses for measurement and used gas. Moreover it displays an in situ measurement medium integrated into the biaxial tensile test machine (Figure 2).

Mean flow pore sizes and pore size distributions within fabrics were determined using the above-mentioned modified instrument in accordance with testing methods ASTM E 1294-89 and ASTM F316-03. A perfluorocarbon (surface tension $\sigma=16 \mathrm{mN} / \mathrm{m}$ ) was used as testing fluid. The measurements were carried out using a standard measuring head with an area of $2.01 \mathrm{~cm}^{2}$. Flow rate range and maximum pressure were set to $0.06-70 \mathrm{l} / \mathrm{min}$ and $2000 \mathrm{mbar}$, respectively. The differential pressure across the samples in dependence on the flowrate was measured for dry and wet samples. The test fluid used should fill all pores completely without affecting the pore size distribution. Permeability-weighted pore size distribution was calculated from the pressure drop vs. the volumetric flow rate of the sample in wet and dry conditions. Mean flow pore size corresponding to the pressure drop was calculated where the wet flow value is half of the dry flow (Figure $3 \mathrm{a}$ ). The basic configuration of the device is shown in Figure 3b. Two highprecision mass flow controllers were used to generate a defined flow rate which is passed through the test sample. The resulting differential pressure was measured by pressure sensors (Figure 3).

\section{Biaxial loading}

The samples were acclimatized for all tests mentioned below to the standard atmosphere for conditioning according to DIN EN ISO 139. Prior to the application of biaxial tensile loading, the breaking forces of PES high density woven fabrics in warp and weft directions were measured according to textile testing methods based on DIN EN ISO 13934-1. A uniaxial tensile test machine UPM 1445 (Zwick, Germany) was used for the determination of breaking forces. Table 3 shows the breaking forces of fabrics that were used for the analyses. A biaxial tensile test machine (Zwick, Germany) was used for the biaxial loading of samples. Woven fabrics were biaxially loaded in different loading situations, i.e., at $30 \%, 40 \%$ and $50 \%$ of their breaking loads (Table 3 ).

In order to avoid as possible from the squeezing of the transverse deformation with biaxial loading, a cross sample with dimensions given in Figure 4 was used to reduce the influence of clamping on squeezing. Due to parallel slits on the sample, there will be less squeezing caused by 
Citation: Kocaman RT, Malik SA, Aibibu D, Gereke T, Cherif C (2018) New Method for In-situ Measurement of Pore Size Deformation of Barrier Textiles under Biaxial Loading. J Textile Sci Eng 8: 355. doi: 10.4172/2165-8064.1000355

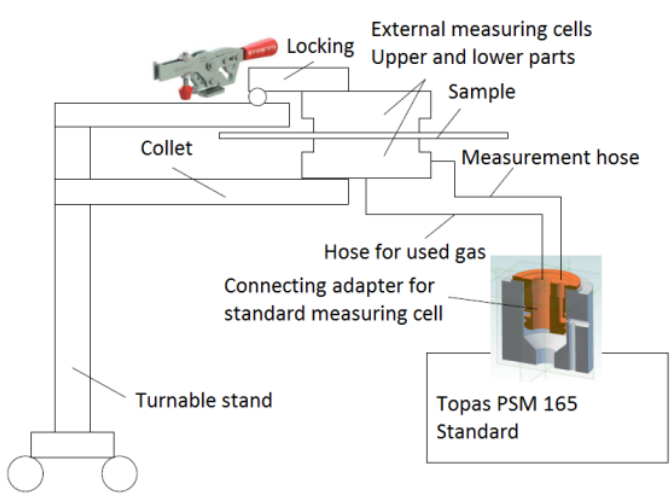

(a)

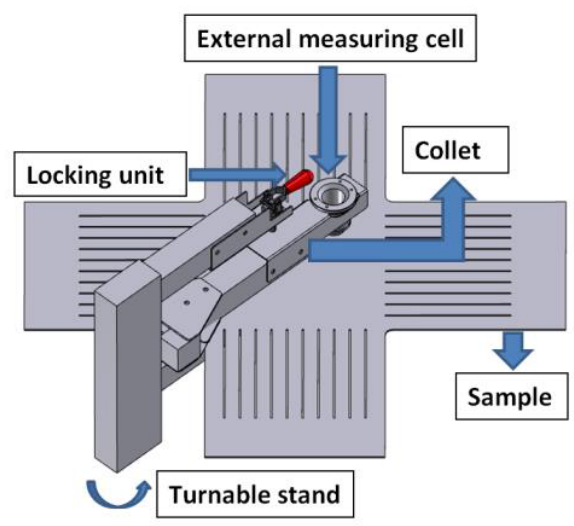

(b)

Figure 1: Measuring unit (a) and CAD view of the sample holder with cross sample (b) (Topas, Germany).

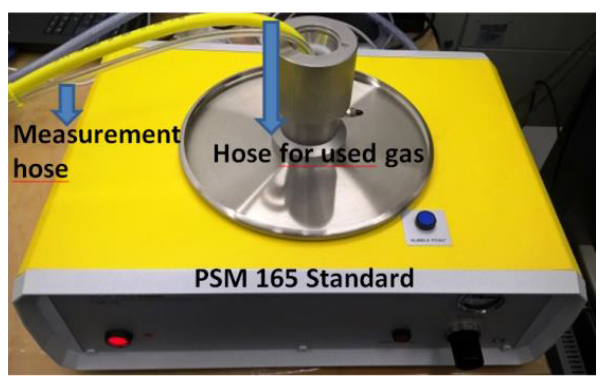

(a)

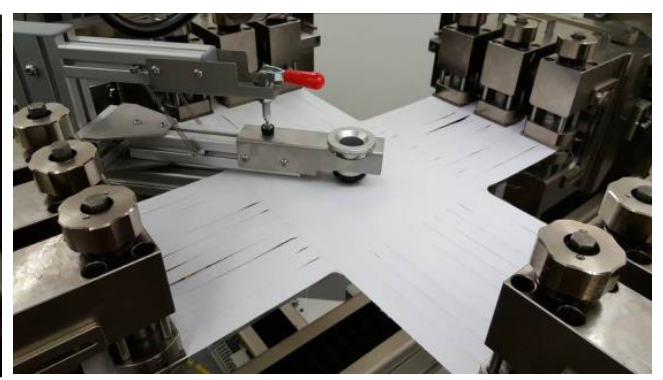

(b)

Figure 2: Special sample holder connected to the test instrument (a) and in situ measurement of pore sizes under biaxial loading (b).

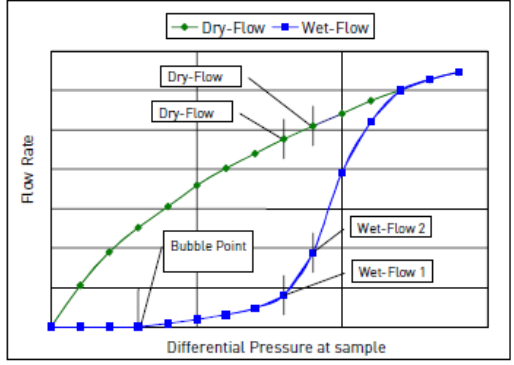

(a)

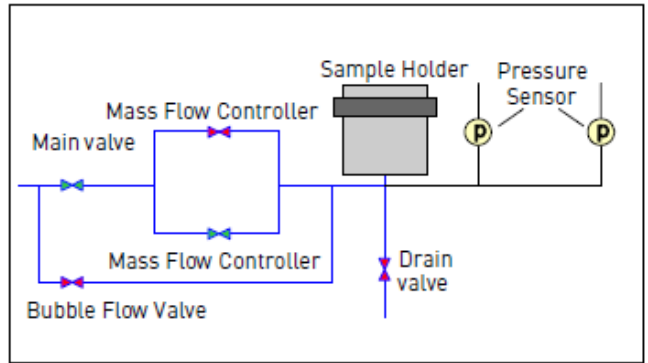

(b)

Figure 3: Measured pressure drop vs. flow rate for dry and wet samples (a) and basic scheme of measuring (b).

\begin{tabular}{|c|c|c|c|c|}
\hline Sample number & $\begin{array}{l}\text { Breaking force in warp direction } \\
\qquad[\mathrm{N}]\end{array}$ & $\begin{array}{l}\text { Standard deviation } \\
{[\mathrm{N}]}\end{array}$ & $\begin{array}{l}\text { Breaking force in weft direction } \\
\qquad[\mathrm{N}]\end{array}$ & $\begin{array}{l}\text { Standard deviation } \\
{[\mathrm{N}]}\end{array}$ \\
\hline 1 & 1070 & 67.5 & 679 & 7.9 \\
\hline 2 & 1080 & 88.1 & 659 & 20.9 \\
\hline 3 & 1120 & 28.6 & 659 & 13.2 \\
\hline 4 & 1120 & 60.8 & 690 & 6.9 \\
\hline 5 & 1190 & 53.0 & 433 & 11.5 \\
\hline 6 & 1220 & 18.9 & 502 & 6.7 \\
\hline 7 & 1320 & 69.4 & 758 & 10.5 \\
\hline 8 & 1350 & 52.4 & 911 & 8.5 \\
\hline 9 & 1150 & 67.3 & 660 & 14.3 \\
\hline 10 & 1100 & 35.6 & 842 & 11.0 \\
\hline 11 & 1170 & 64.1 & 833 & 13.6 \\
\hline
\end{tabular}

Table 3: Breaking force values of PES woven fabrics. 
transverse deformation. These samples could be tested with segmented loading. The sample dimensions were adapted according to the testing method based on MSAJ/M-02-1995, where the used dimensions were devised for membrane structures. The preparing of samples, type of biaxial loading and extension rate were based on study [16]. Fabrics were loaded continuously on the biaxial tensile test machine with a preloading force of $5 \mathrm{~N}$, and the machine was set to an extension rate of $5 \mathrm{~mm} / \mathrm{min}$ up to $30 \%, 40 \%$ and $50 \%$ of breaking forces and the porosity measurements were done for every level of loading. Furthermore, the barrier fabric samples were subjected to cyclic biaxial loadings of up to $40 \%$ of their breaking force for the detailed analyse of mean flow pore size changes. The samples were elongated for 30 cycles using a $25 \mathrm{~mm} /$ min extension rate and mean flow pore size measurements $(n=5)$ were performed under the following biaxial loading (Figure 4).

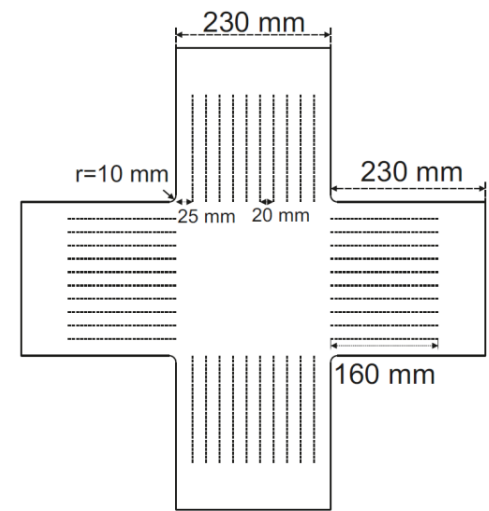

Figure 4: Sample dimensions for biaxial testing adapted from the testing method according to the norm MSAJ/M-02-1995.

\section{Results and Discussion}

\section{Pore size distribution under biaxial loading}

Figure 5 shows the pore size distributions of selected samples whose construction and process parameters were provided in Table 2. Pore size distributions of samples without biaxial tensile loadings are also displayed in the following graphs. It is clearly visible that, in the case of all samples, the pore size distribution changed due to application of the biaxial load. Furthermore, it was observed that pore sizes increased with an increase in biaxial tensile loads. The largest change was reported for sample 5, whereas the least pronounced change was reported for sample 2 . In the case of sample 5 the maximum pore size was around $16.4 \mu \mathrm{m}$ without biaxial loading and grew by $50 \%$ biaxial loading to approx. 220 $\mu \mathrm{m}$ (Figure 5a). Under this biaxial loading, $16.4 \%$ of the pores were larger than $16.4 \mu \mathrm{m}$, which proves that these pores occur after biaxial loading. Larger inter-yarn pores in the plain woven fabrics resulted in more enlarged pores after biaxial loading according to comparisons between samples 2, 5 and 6 . The reason causing larger pore sizes in sample 5 might be that these samples had larger inter-yarn pores due to its lower weft density. Theoretically, the number of inter-yarn pores was less than the number of inter-yarn pores in the other variants; however, the enlargement in this sample construction might lead to larger interyarn pores after tensioning. Figure 6 illustrates the change in pore size distribution of sample 2 with biaxial loading as an example. Sample 2 exhibited a maximum pore size of $8.75 \mu \mathrm{m}$ without tension. Under biaxial loading of $50 \%$ of the breaking force, $19.1 \%$ of pores were larger than $8.75 \mu \mathrm{m}$ (Figure $5 \mathrm{c}$ ). The maximum pore size was $46.8 \mu \mathrm{m}$ under this type of biaxial loading, which is smaller than the one in sample 5 . Sample 6 had a maximum pore size of $80.9 \mu \mathrm{m}$ which was smaller than that in sample 5 as well, but exceeded that in sample 2 (Figure $5 b$ ). Thus, samples with smaller weft densities exhibited larger pore size changes under tension (Figure 5).

Sample 9 had a maximum pore size of $8.6 \mu \mathrm{m}$ in an untensioned state. Under $40 \%$ biaxial loading, $33.3 \%$ of pores were larger than 8.6 $\mu \mathrm{m}$, i.e., there was a considerable increase in pore sizes compared to sample 2 (Figure $5 \mathrm{~d}$ ). A potential reason for this behaviour could be the influence of yarn construction on permeability properties. Multifilament yarns reduce air permeability of the multifilament woven fabrics with an increase in filament number [7]. In contrast, under biaxial loading, this sample revealed a different tendency. In tensioned state, more inter-yarn pores appeared when compared to sample 2. This finding is also applies to sample 10, which contains textured weft yarns. However, sample 10 showed a wider range of pore sizes under $30 \%$ than under $40 \%$ tension (Figure $5 \mathrm{e}$ ). The reason for this tendency is unknown. It is assumed that the effects of both filament fineness and yarn construction on porosity have partially uncertain effects which resulted in complex changes in pore sizes under tension. Sample 11 also shows a different tendency compared to sample 2 according to the fineness of weft yarns included. The change in pore size distribution was clearly detectable after $30 \%$ biaxial loading (Figure $5 \mathrm{f}$ ). This could be due to the thicker weft yarn used in sample 11. Twill weave showed a different tendency when compared to plain weave having identical fabric indices. Under biaxial loading of $50 \%$ of the breaking force, only $5.8 \%$ of the pores of sample 7 were larger than the maximum pore size determined without tension, which was $15.2 \mu \mathrm{m}$ (Figure $5 \mathrm{~g}$ ). This value was $16.4 \%$ for the plain woven sample 5 (Figure $5 \mathrm{a}$ ). Biaxial loading seems to have less impact on pore sizes of twill weave compared to plain weave. The main reasons could be differences in the binding of the fabrics which affect the permeability properties of these types of woven fabrics as well [7]. Moreover, weft density is a potential cause. Twill weaves with an identical fabric index as plain weave have a higher weft density. In twill woven fabrics, the enlargements of inter-yarn pores is not identical with plain woven fabrics. In $1 / 1$ plain woven fabrics, a better orientation of yarns in the $0^{\circ}$ and $90^{\circ}$ directions can be achieved compared to $2 / 2$ twill woven fabrics. This difference in orientation could affect the enlargement of inter-yarn pores under biaxial loading. Moreover, there was not a mentionable change in the pore size range of sample 7 under a biaxial loading of $30 \%$ of breaking force. Notable change occurred after $40 \%$, and the maximum pore size increased from $15.2 \mu \mathrm{m}$ to $42 \mu \mathrm{m}$ under $40 \%$ biaxial loading.

\section{Mean flow pore sizes}

Samples were evaluated with respect to their mean flow pore sizes in order to investigate the effects of fabric construction, yarn construction, weaving and process parameters after biaxial cyclic loadings. Five measurements were taken for the evaluation of mean flow pore sizes and deviations were illustrated within the diagrams. Figure 7-a shows the comparison of three $1 / 1$ plain woven samples with different fabric indices (Figure 7).

It was observed that with a decrease in fabric index (by decreasing weft density), the mean flow pore size of the fabric increased. This conclusion seems to be valid under biaxial loading as well. Under biaxial loading of $40 \%$ and after 30 cycles, mean flow pore sizes of the samples increased.

Comparisons between four plain woven samples processed with different machine speeds are given in Figure $7 \mathrm{~b}$. An increase in mean flow pore sizes under biaxial loading was clearly detected for every 
Citation: Kocaman RT, Malik SA, Aibibu D, Gereke T, Cherif C (2018) New Method for In-situ Measurement of Pore Size Deformation of Barrier Textiles under Biaxial Loading. J Textile Sci Eng 8: 355. doi: 10.4172/2165-8064.1000355

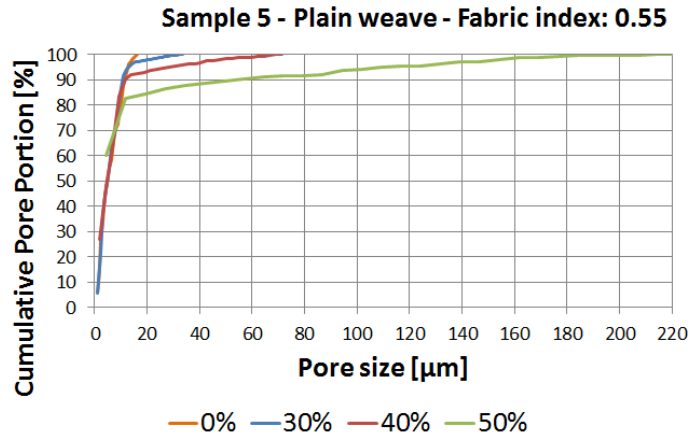

(a)

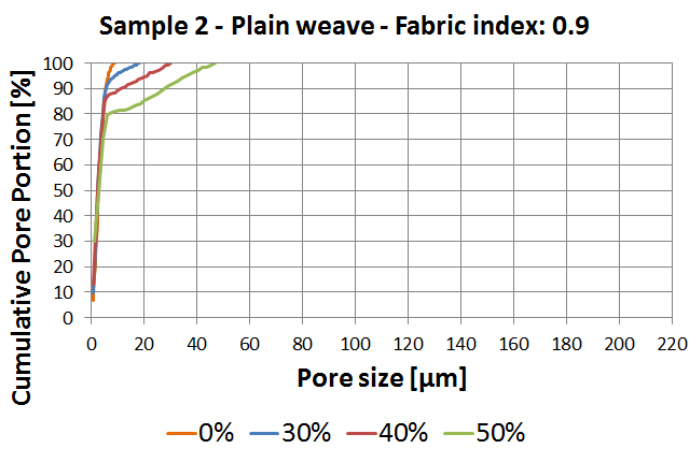

(c)

\section{Sample 10 - Plain weave - Fabric index: 0.9 - Y3}

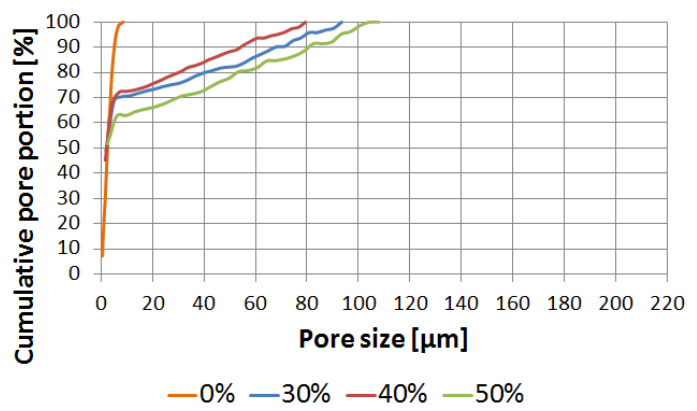

(e)

Sample 7 - Twill weave - Fabric index: 0.55

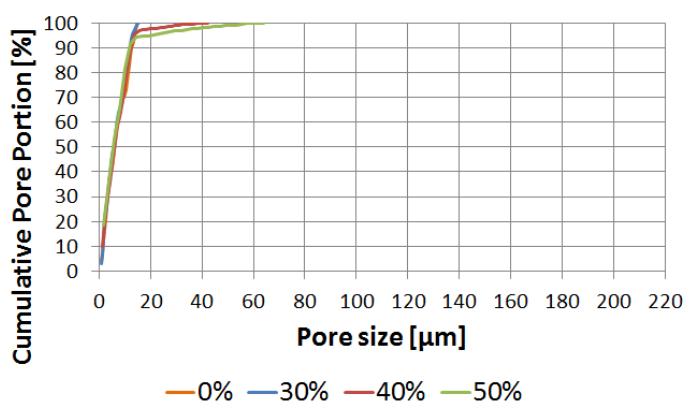

Sample 6 - Plain weave - Fabric index: 0.68

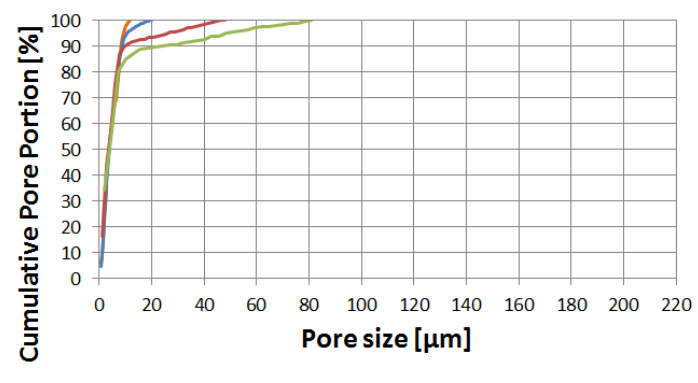

$-0 \%-30 \%-40 \%-50 \%$

(b)

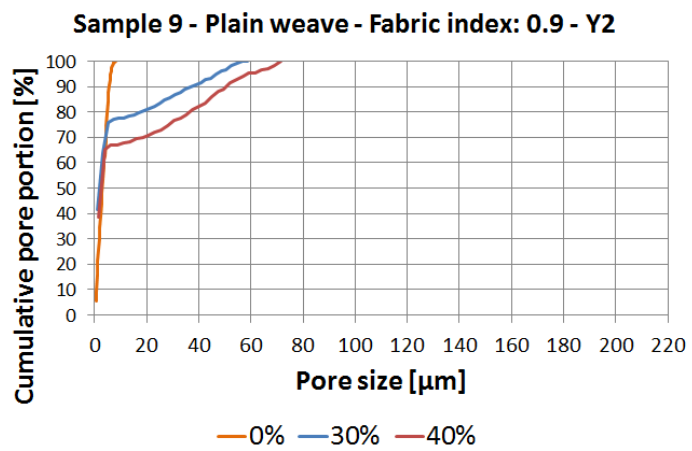

(d)

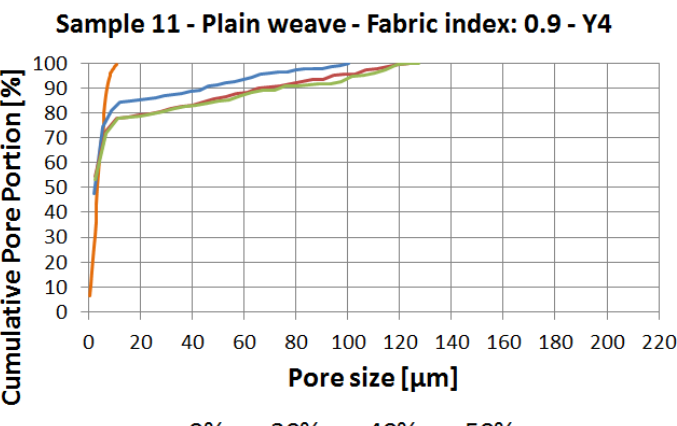

(f)

(g)

Figure 5: Pore size distribution diagrams as cumulative pore portion (Y2: Yarn 2 (100 dtex f128 flat), Y3: Yarn 3 (100 dtex f80 textured), Y4: Yarn 4 (150 dtex f48 glatt)). 


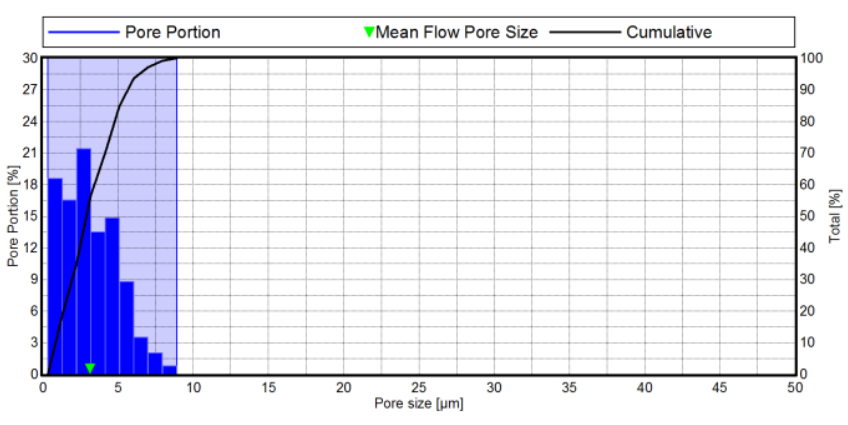

a) Without loading

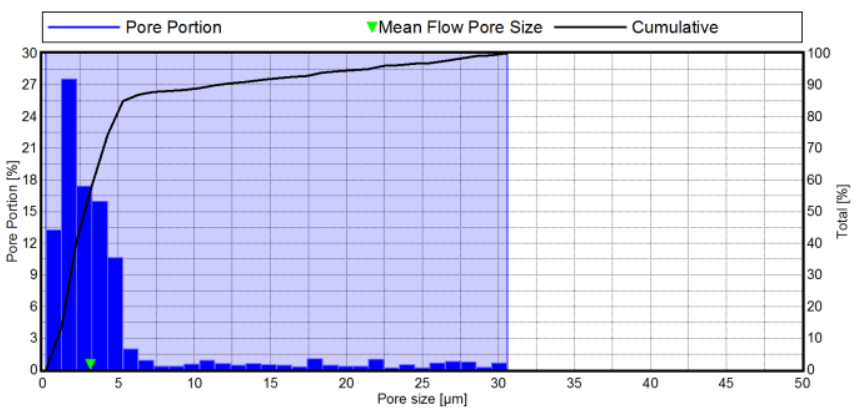

c) $40 \%$ biaxial loading

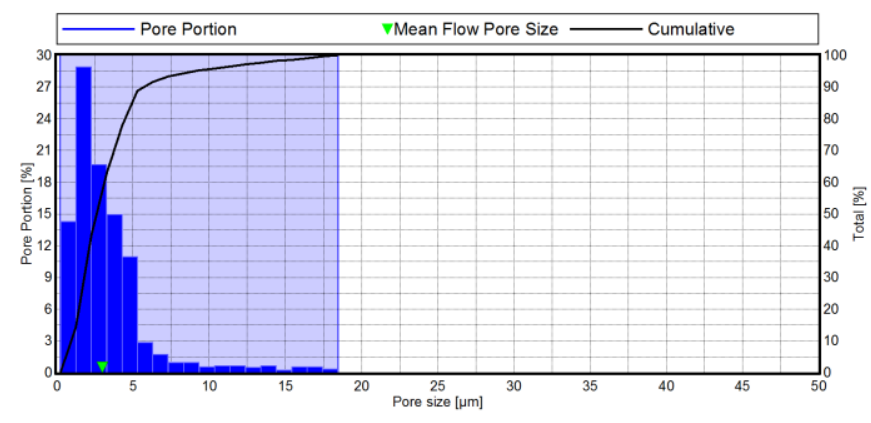

b) $30 \%$ biaxial loading

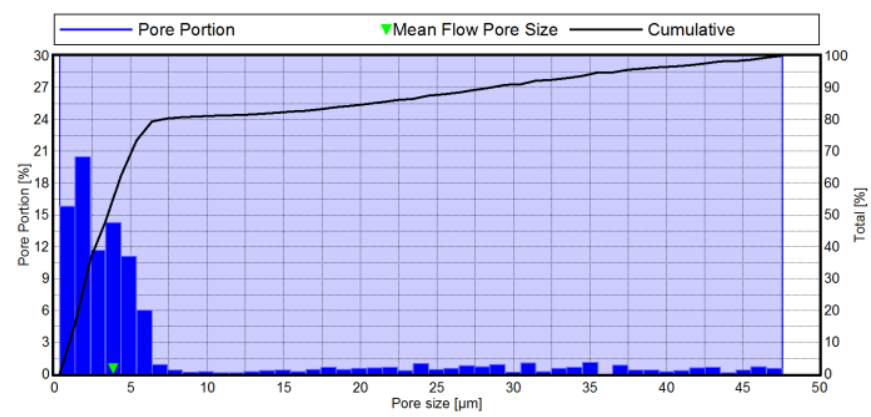

d) $50 \%$ biaxial loading

Figure 6: Changes in pore size distribution of sample 2 under biaxial loading.

sample. However, there was no explicit trend of mean flow pore size values of samples in terms of machine speed. Only minor changes were observed. A comparison of two twill $2 / 2$ woven samples with different fabric indices is presented in Figure 7c. It was observed that the twill woven samples follow a different trend than plain woven samples under biaxial loading. The increase in mean flow pore size value under tension is very small compared to plain woven samples. This could be due to the small change in pore size range, which was already discussed in previous sections. Both findings prove that biaxial loading has not significant effect on pore size changes at loads of up to $40 \%$. A decrease in mean flow pore size values by increasing the fabric density was also confirmed for twill woven samples. Mean flow pore size values of two plain woven samples with identical fabric indices, but with different yarn types are shown in Figure 7d. Both the samples showed an increase in mean flow pore size values; however this increase was more prominent in sample 9 which has yarn 2 as weft yarn. Sample 9 exhibited a lower value of mean flow pore size than sample 2 in unloaded state. This may result from the number of filaments, which changes the permeability properties of woven fabrics by affecting yarn packing. Nevertheless, it cannot be stated that sample 9 preserves its barrier properties under biaxial loading. A comparison between mean flow pore size values of two plain woven samples with the identical fabric indices but different yarn types is also given in Figure 7e. higher yarn fineness led to an increase in mean flow pore sizes for both conditions. Changes in mean flow pore size values before and during biaxial loading seem to be equal for both samples.

\section{Conclusion}

Based on the promising approach of liquid displacement methods, a novel and unique non-destructive in situ method for continuous analysing of the changes in pore size deformations of high density barrier fabrics under biaxial loading was developed within the presented research work. According to extensive literature studies, currently, there is no comparable non-destructive in situ pore analysing method under biaxial loading.

It was observed that pore size distributions and mean flow pore size values appear to change under biaxial tensile loads and this change strongly depends on the fabric construction and loading level. In general, the pore size distribution of plain woven samples is more likely to change under biaxial loading than the pore size distribution of twill woven samples. The increase in pore size in plain weaves was more pronounced than the increase in pore size in twill weaves. Furthermore, there was no notable change in pore size under tensile biaxial loads of $30 \%$ of the breaking force for twill woven sample, whereas significant changes were observed at $40 \%$ of the breaking force. The changes in pore size under biaxial loading differed depending upon fabric index, fabric construction and yarn construction. Samples with a small fabric index showed more pore size changes under biaxial loading. By increasing the number of filaments in the yarn cross section and using textured weft yarn, pore size distributions with smaller pore sizes were observed without loading. However, the samples containing these yarns exhibited a huge increase in pore sizes when compared to the model sample. An increase in mean flow pore size values was also observed under biaxial tensile loading. This change was more prominent in plain weaves compared to twill weaves.

Twill woven samples showed a minor increase in mean flow pore sizes under biaxial loading. This observation was also valid for different fabric indices. A conclusion regarding the effect of cyclic biaxial loading on mean flow pore size properties cannot be drawn due to minor decrease. In addition, no clear trend of mean flow pore sizes with respect to machine speed was detected, even though changing the 
Citation: Kocaman RT, Malik SA, Aibibu D, Gereke T, Cherif C (2018) New Method for In-situ Measurement of Pore Size Deformation of Barrier Textiles under Biaxial Loading. J Textile Sci Eng 8: 355. doi: 10.4172/2165-8064.1000355

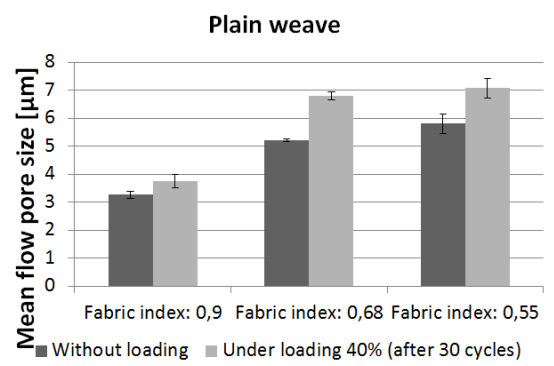

a) Mean flow pore sizes of plain weaves with respect to fabric index

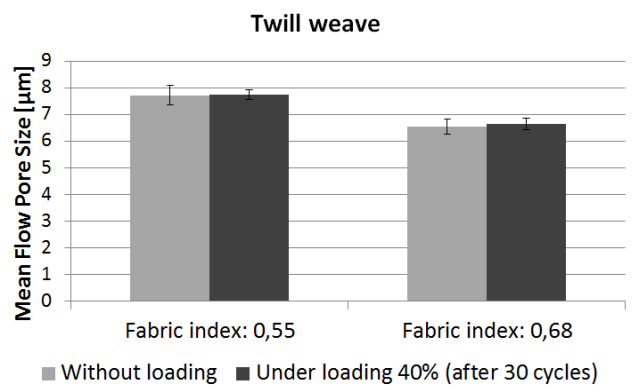

c) Mean flow pore sizes of twill weaves with respect to fabric index

Plain weave

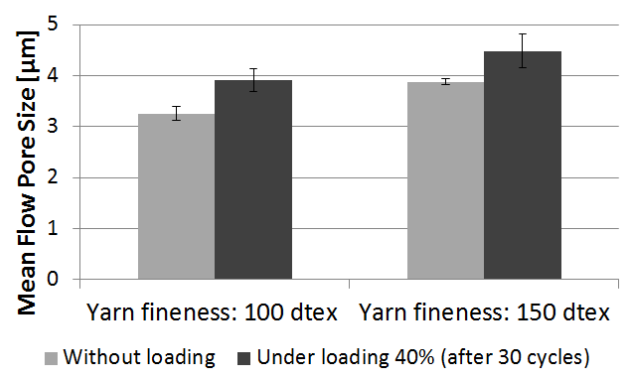

e) Mean flow pore sizes with respect to yarn fineness

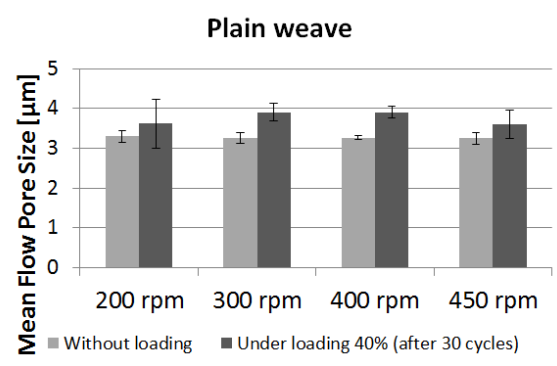

b) Mean flow pore sizes with respect to machine speed

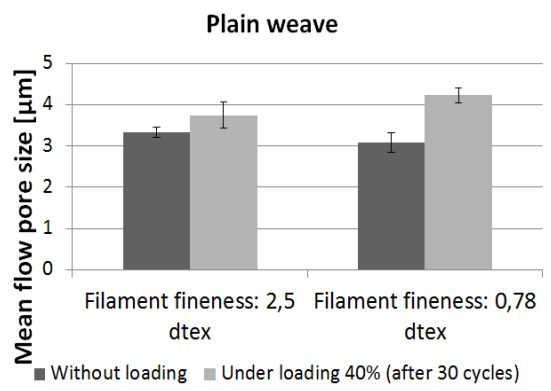

d) Mean flow pore sizes with respect to filament fineness

Figure 7: Mean flow pore size values of samples without loading and under biaxial loading (after cyclic loading) with respect to fabric index, binding, machine speed, filament fineness and yarn fineness.

machine speed resulted in minor differences in mean flow pore sizes after biaxial cyclic loading. An increased filament number in the yarn cross section led to a decrease in mean flow pore size. However, under biaxial loading, the sample had higher mean flow pore sizes and could not protect its barrier properties.

\section{Acknowledgement}

The authors would like to thank the German Research Foundation (Deutsche Forschungsgemeinschaft) for its support of the research project DFG CH 174/26-2.

\section{References}

1. Leonas K (1998) Effect of laundering on the barrier properties of reusable surgical gown fabrics. Am J Infect Control 26: 495-501.

2. Jain R, Raheel M (2003) Barrier efficacy of woven and nonwoven fabrics used for protective clothing: Predictive models. Bull Environ Contam Toxicol 71: 437446

3. Nagy V, Vas LM (2005) Pore characteristic determination with mercury porosimetry in polyester staple yarns. Fibres Text East Eur 13: 21-26.
4. Benesse M, Le Coq L, Solliec C (2006) Collection efficiency of a woven filter made of multifiber yarn: Experimental characterization during loading and clean filter modeling based on a two-tier single fiber approach. J Aerosol Sci 37 974-989.

5. Kuhr M, Aibibu D, Cherif C (2016) Targeted partial finishing of barrier textiles with microparticles, and their effects on barrier properties and comfort. J Ind Text 45: 853-878.

6. Leonas K, Jinkins R (1997) The relationship of selected fabric characteristics and the barrier effectiveness of surgical gown fabrics. Am J Infect Control 25: 16-23.

7. Laourine E, Cherif C (2011) Characterisation of barrier properties of woven fabrics for surgical protective textiles. Autex Res J 11: 31-36.

8. Zupin Z, Hladnik A, Dimitrovski K (2012) Prediction of one-layer woven fabrics air permeability using porosity parameters. Text Res J 82: 117-128.

9. Ogulata RT, Mezarcioz S (2012) Total porosity, theoretical analysis, and prediction of the air permeability of woven fabrics. J Text Inst 103: 654-661.

10. Xu G, Wang F (2005) Prediction of the permeability of woven fabrics. J Ind Text 34: 243-254. 
Citation: Kocaman RT, Malik SA, Aibibu D, Gereke T, Cherif C (2018) New Method for In-situ Measurement of Pore Size Deformation of Barrier Textiles under Biaxial Loading. J Textile Sci Eng 8: 355. doi: 10.4172/2165-8064.1000355

11. Xiao $X$, Zeng $X$, Long $A$, Lin $H$, Clifford $M$, et al. (2012) An analytical model for through-thickness permeability of woven fabric. Text Res J 82: 492-501.

12. Havlová M. (2012) Air permeability and costructional parameters of woven fabrics. Fibres Text East Eur 21: 84-89.

13. Altman K, McElhaney J, Moylan J, Fitzpatrick K (1991) Transmural surgical gown pressure measurements remits in the operating theater. Am $\mathrm{J}$ Infect Control 19: 147-155.

14. Smith JW, Nichols RL (1991) Barrier efficiency of surgical gowns-are we really protected from our patients pathogens. Arch Surg 126: 756-763.

15. Smith J, Tate W, Yazdani S, Garcia R, Muzik A, et al. (1995) Determination of surgeon-generated gown pressures during various surgical procedures in the operating room. Am J Infect Control 23: 237-246.

16. Rief S, Glatt E, Laourine E, Aibibu D, Cherif C, et al. (2011) Modeling and CFDSimulation of woven textiles to determine permeability and retention properties. Autex Res J 11: 78-83.

17. Pietsch K (2010) Untersuchungen zur Reproduzierbarkeit der Struktur-Eigenschaftsrelationen von Operationsschutztextilien unter Gebrauchsbedingungen. PhD Study. Technische Universität Dresden

18. Hedfi H, Ghith A, BelHadjSalah H (2011) Dynamic fabric modelling and simulation using deformable models. J Text Inst 102: 647-667.

19. Dubrovski PD, Brezocnik M (2012) The usage of genetic methods for prediction of fabric porosity: Genetic programming - New approaches and successfu applications. InTech

20. Rukuiziene Z, Milasius R (2006) Inequality of woven fabric elongation in width and change of warp inequality under axial and bi-axial tensions. Fibres Text East Eur 14: 36-38.

21. Aibibu D, Lehmann B, Offermann $P$ (2003) Barrier effect of woven fabrics used for surgical gowns. Autex Res J 3: 186-193.

22. Gong RH, Newton A (1992) Image-analysis techniques. Part I: The Measurement of pore-size distribution. J Text Inst e 83: 253-268.

23. Chang T, Zhang J, Fuch Y (2014) Electrical, mechanical and morphological properties of compressed carbon felt electrodes in vanadium redox flow battery. J Power Sources 245: 66-75.

24. Mühl T, Binnebösel M, Klinge U, Goedderz T (2007) New objective measurement to characterize the porosity of textile implants. J Biomed Mater Res, Part B 84: 176-183.

25. Klinge U, Otto J, Mühl T (2015) High structural stability of textile implants prevents pore collapse and preserves effective porosity at strain. Biomed Res Int 2015: 1-7.

26. Sieminski MA, Hotte G H (1944) The porosity of the textile materials. Rayon Text Mo 25: 608-610.

27. Burleigh E, Wakeham H, Honold E, Skau E (1949) Pore-Size Distribution in Textiles. Text Res J 19: 547-555.

28. Wakeham H, Spicer N (1949) Pore-size distribution in textiles - A study of windproof and water-resistant cotton fabrics. Text Res J 19: 703-710.

29. Bhatia SK, Smith JL (1995) Application of the bubble point method to the characterization of the pore-size distribution of geotextiles. Geotech Test $\mathrm{J} 18$ 94-105.

30. Li D, Frey MW, Joo YL (2006) Characterization of nanofibrous membranes with capillary flow porometry. J Membr Sci 286: 104-114.

31. Lee Y, Jeong J, Youn I, Lee W (1997) Modified liquid displacement method for determination of pore size distribution in porous membranes. J Membr Sci 130: $149-156$.

32. Walz F, Luibrand J (1947) Die Gewebedichte. Textil Praxis Bd 2: 330-335.

33. Malik SA, Kocaman RT, Kaynak HK, Gereke T, Aibibu D, et al. (2017) Analysis and prediction of air permeability of woven barrier fabrics with respect to material, fabric construction and process parameters. Fibers Polym 18: 2005 2017.

34. Hild M, Brünler R, Jäger M, Laourine E, Scheid L, et al. (2014) Net Shape Nonwoven: a novel technique for porous three-dimensional nonwoven hybrid scaffolds. Text Res J 84: 1084-1094.

35. Brünler R, Aibibu D, Wöltje M, Anthofer A, Cherif C (2017) In silico modeling of structural and porosity properties of additive manufactured implants for regenerative medicine. Am J Mater Sci Eng 76: 810-817.

36. Große S, Adam R, Rudolph A (2010) Application of non-mercury porometric measurements for structural characterization of various filter media [PowerPoint presentation]. Topas GmbH (Accessed: 19 March 2018) 